\title{
Computer Assisted Instruction System Under Artificial Intelligence Technology
}

\author{
https://doi.org/10.3991/ijet.v16i05.20307 \\ Jingjing Zhang \\ Jingdezhen Ceramic University, Jingdezhen, China \\ zhangjingjing-1227@163.com
}

\begin{abstract}
In order to promote the development of intelligent teaching system, artificial intelligence technology is combined with computer assisted instruction (CAI) system to produce intelligent CAI (ICAI), and the design of ICAI is studied in order to facilitate the application and implementation of intelligent teaching system. First, there is an introduction of the basic concepts, related theories, and implementation principles of ICAI. Then, the requirements of ICAI are analyzed in detail on the basis of studying the relevant technologies required by ICAI, including the functional and non-functional requirements. The subsystem is set based on the different needs of the target users (administrator, teacher, and student users). Finally, the general and functional structure of ICAI are designed, and there are tests for the system functions. The results show that the system takes Java Server Pages (JSP) as the development language, Struts2 as the technical framework, and SQL Server 2008 as the back-end database, which realizes a teaching platform mainly for teachers, students, and administrators. After testing, the overall operation of the system is good, and the functional test results of the login module, homework release, and learning resource upload meet the software design requirements. The response time of the system prolongs, the number of users who can't successfully log in grows, and the utilization of server central procession unit (CPU) and memory utilization both increase, which are caused by the increasing number of concurrent users. The results indicate that the combination of CAI and artificial intelligence (AI) technology can meet students' online teaching demands, break the time-space limitation of traditional teaching, and provide important reference value for the reform of teaching mode and the improvement of teaching quality.
\end{abstract}

Keywords - Artificial intelligence; computer assisted instruction; Java Server Pages, intelligent computer assisted instruction; teaching mode

\section{Introduction}

CAI first appeared in the 1950s [1]. With the rapid development of computer technology, CAI has been continuously developed and improved in education, and the teaching mode and concepts have undergone profound changes. The application of computer network technology for auxiliary teaching has become a second teaching in 
addition to classroom teaching [2, 3]. Computer is an indispensable teaching tool in the modern teaching process. CAI has various forms to meet the new requirements of the society for the ability and quality of talents [4]. In the traditional CAI, the teacher inputs the teaching content into the courseware, so the content students learn is predetermined. There is a lack of information interaction between teachers and students, so that teachers can't teach in accordance with their aptitude and the teaching content can't be updated and maintained at any time $[5,6]$. Computers are employed by AI to simulate human intelligent behavior and activities [7]. The emergence of AI provides new ideas for CAI. At present, CAI is gradually developing towards network and

Intelligence. ICAI has become a hot topic of current CAI research $[8,9]$. ICAI uses human cognitive ability as its theoretical thinking, and applies AI in CAI to realize and improve the teaching practice activities. As a product of AI in pedagogy, ICAI can not only fully mobilize students' learning enthusiasm and increase their interest in learning, but also provide personalized teaching according to their own characteristics. Thus, it is conducive to teaching students in accordance with their aptitude, is not limited by time and space, and facilitates the promotion and dissemination of excellent teaching methods $[10,11]$.

Therefore, AI is combined with CAI to design and develop ICAI based on its advantages, the related technologies of ICAI are introduced, and the general and functional structure designs of ICAI are completed on the basis of requirement analysis. Finally, there are the function implementation and testing for the functions of ICAI. The objective of this study is to provide important reference for promoting the development of intelligent teaching system.

\section{Methods}

\subsection{Introduction to intelligent computer assisted instruction system}

ICAI is an expert system based on knowledge teaching, which can not only make intelligent reasoning analysis of relevant teaching knowledge, improve and optimize teaching strategies, and produce courseware automatically, but also conduct teaching evaluation according to students' knowledge mastery [12]. ICAI overcomes the shortcomings of the traditional $\mathrm{CAI}$ and has the following advantages, including evaluation of student learning and teacher teaching behaviors, human-computer interaction, intelligent error correction, automatic generation of exercises and answers, automatic adjustment of learning content and progress, and continuous improvement of teaching strategies.

CAI was born in 1959, which was developed by International Business Machine (IBM), and the related theoretical foundation has undergone three major evolutions. In the initial stage of CAI development, it is based on behaviorist learning theory. Behavioral learning theory does not pay attention to internal psychological processes but emphasizes that learning is a response to external stimuli. Therefore, cognitive learning theory emerged later. Cognitive learning theory believes that the work of teachers is no longer just a transmitter of knowledge but a promoters of learning. 
Since the 1990s, constructivism has become the theoretical basis of CAI. Constructivism has proposed a student-centered teaching model under the guidance of teachers, which emphasizes the role of students as the subject of cognition and is different from the previous teacher-centered teaching model [13].

ICAI has the characteristics of teacher guidance. Teachers can guide them based on the learning characteristics of students, which can also be completed by ICAI, which can determine the learning content according to the characteristics of students' learning behaviors to achieve heuristic and personalized teaching. ICAI is usually composed of four parts, namely knowledge base, student model, teacher model, and human-computer interface, as shown in Figure 1.

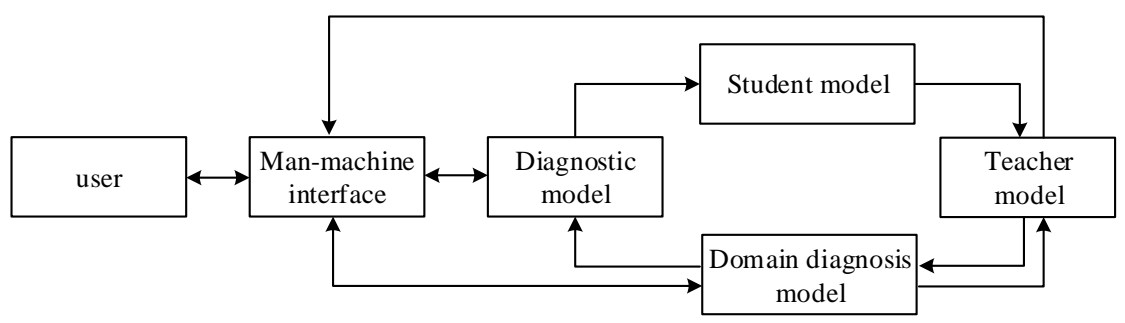

Fig. 1. ICAI system structure diagram

The knowledge base includes the student knowledge and teacher knowledge base. The student knowledge base is employed to record the personal information of students, including knowledge level, learning ability, comprehensive ability, and learning progress. The teacher knowledge base is applied to store some teaching methods, teaching knowledge, and problem-solving methods. The student model is the key to ICAI's personalized teaching and provides a critical basis for the realization of personalized teaching. The student model can clearly reflect the learning ability and knowledge level of the teaching object. The teacher model is an important center for organizing, managing, and implementing teaching activities. It mainly includes teaching experience and reasoning strategies, and plays a controlling and coordinating role in the whole system of ICAI. The human-computer interface is a medium for transferring information between students and the system. The combination of natural language and graphics is adopted in this system, which is more intuitive and vivid.

\subsection{Technologies related to intelligent computer assisted instruction system}

JSP technology: JSP is a dynamic web page technology standard, usually composed of web page Hypertext Markup Language (HTML) files, Java program fragments, and JSP tags [14]. JSP is based on Java language and can realize crossplatform operation. The JSP running process is shown in Figure 2. When the JSP page is run for the first time, the JSP file needs to be translated into a Java file format by the JSP engine and converted into executable code. Then, the result is output to the server, and the server converts the running result into HTML format for transmission to the client browser. Due to the first time of JSP page running, it needs to go through 
a series of steps such as translation, compilation, and transcoding, so the response time will be slightly longer. But when the page is run again, there is no need to go through the process of translation and compilation, and the access speed is greatly improved.

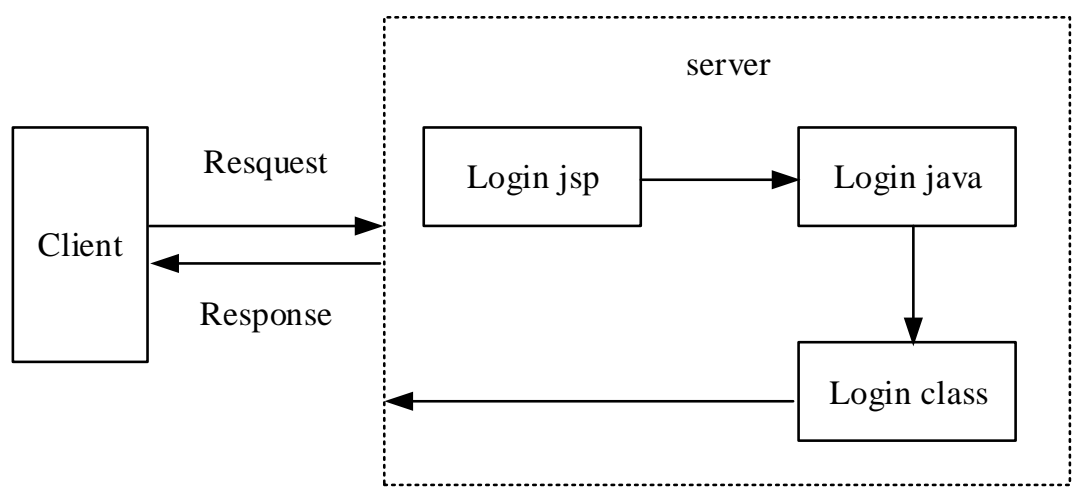

Fig. 2. JSP running process

MVC framework: Struts technology of MVC frameworks is employed in this study. The mainstream frameworks currently applied are all based on Servlet and JSP technology. Struts technology combines Servlet and JSP into the same framework to form a full set of MVC mode, which has the advantages of no coding and time saving, so it is extensively used in various auxiliary teaching systems [15]. Struts2 is an upgraded version and is an MVC framework developed based on Webwork. The main process is shown in Figure 3.

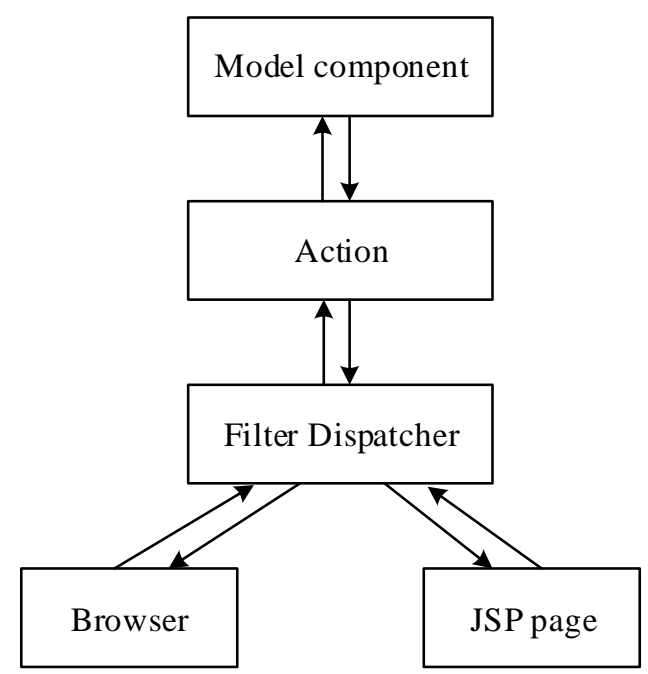

Fig. 3. Struts2 flow chart 
Database storage technology: Database is the core part of information system, which can efficiently realize data management and integration functions. At present, the common applied databases include SQL Server 2000, SQL Server 2008, Oracle, and Access [16-18]. Access is a small database suitable for simple desktop database programming, and SQL Server 2008 and Oracle are large databases. In this study, SQL Server 2008 is mainly employed to store data. SQL Server 2008 can organize various types of data (such as numbers, pictures, videos, and text), and implement multiple operations (such as search, synchronization, analysis, and reporting). It is also possible to store structured, semi-structured and unstructured document data in the database. Any device can store data, and servers, desktop computers, and mobile devices can control data regardless of storage location.

\subsection{Demand analysis of intelligent computer assisted instruction system}

The AI-based CAI contains three types of users: administrators, teachers, and students. Therefore, it is necessary to analyze the data model requirements of these three types of users. The system function requirements of these three types of users are what the system should fulfill. The goal of the AI-based CAI designed in this study is that students can autonomously perform courseware downloads, video learning, classwork submission, online testing, online Q\&A, and other operations on the server. Teachers can upload their own courseware or teaching resources to the Internet to perform online Q\&A and homework correction; the accounts and permissions of teachers and students can be assigned in the management, and the back-end database of management can be maintained.

There is an analysis on the non-functional requirements of ICAI, which includes 4 aspects. First one is security. The auxiliary teaching system usually involves a lot of user privacy information, so a security system is very necessary. Besides, some privacy technologies and privacy policies can be used in order to improve the security of the system. Second one is software performance. Teachers and students are the main users of assisted teaching systems, and the number of students is relatively large. If multiple people use it at the same time, the server will crash easily, so the actual use can be divided into different grades or time to use. Third one is reliability. There is a backup system, and the backup system will be activated in time if a problem occurs. Database and log files are also backed up in time to avoid losses. Fourth one is interoperability. The user interface design should be simplified as much as possible to avoid complicated functions that make the user experience poor, and to facilitate simple and fast operation for students, which can reflect better human-computer interaction performance.

The requirements of data model can be expressed as follows. Based on the different users and system functions, the intelligent auxiliary teaching system mainly includes data models such as teachers, students, administrators, teaching resources, homework management, and online Q\&A. The administrator is responsible for the maintenance and management of the system, and the database requires account and password information. Teachers are responsible for the management of studentrelated learning tasks. The database needs to have account, password, name, mobile 
phone number, and other information. Students mainly carry out learning-related activities, and the database needs to have account, password, name, gender, and other information. In addition, other modules contain information such as course/examination questions/assignment number and course/examination question/assignment name.

\subsection{Design of computer assisted instruction system based on artificial intelligence technology}

General system structure design: This system model is divided into three parts, including administrator, student, and teacher. The B/S structure is adopted for easy management and use, and the overall framework is shown in Figure 4.

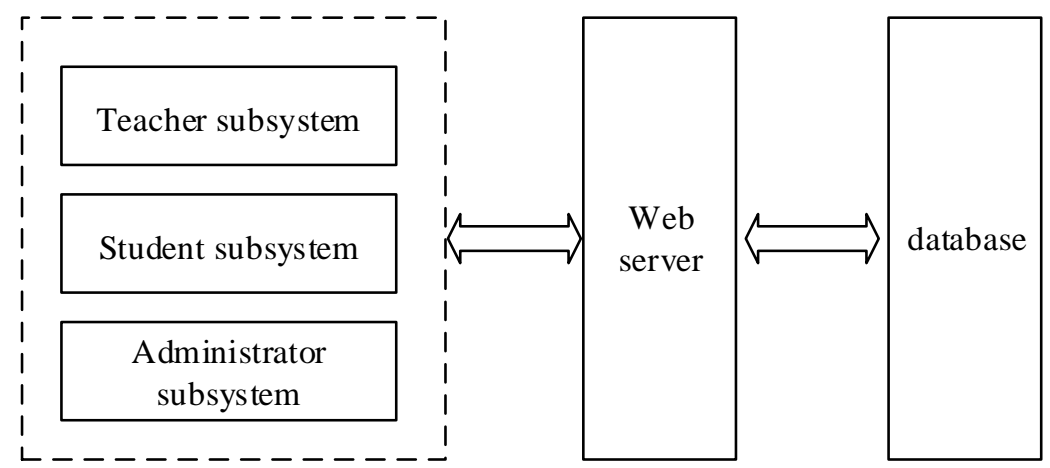

Fig. 4. System overall framework

The system architecture technology is mainly divided into customer layer, page layer, business layer, and data layer (Figure 5). The B/S technology is adopted for the customer layer, and users use the personal computers (PCs) to process business. In the page layer, all requests of users are submitted via the browser, presented in the form of page, and embedded JSP to forward requests. The business layer mainly processes user requests and feeds them back to customers. Moreover, it interacts with the database through JSP technology. The data are stored in the data layer, and the SQL Server database storage technology is applied in this study. 


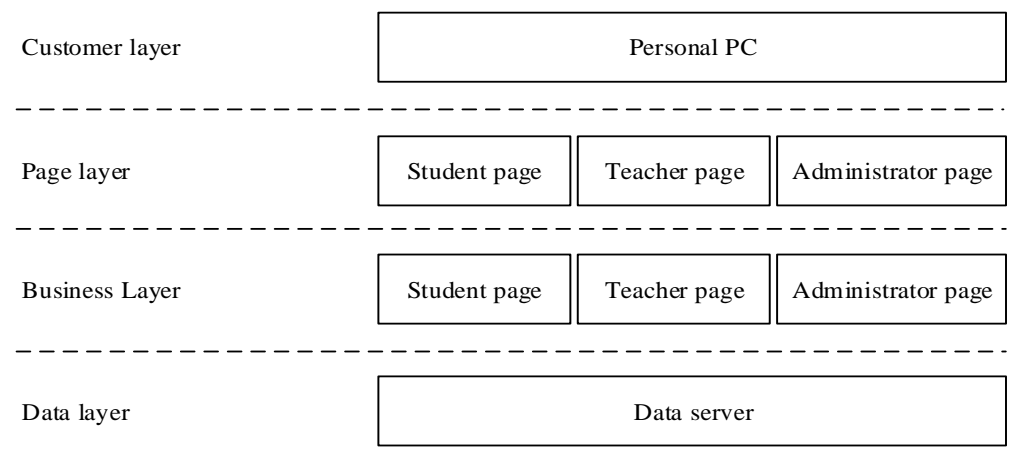

Fig. 5. System architecture technology layering

Functional structure design: The objective of the functional structure design is to make the functions of each module clearer, so that the system is more concise and clear. Administrators, teachers, and students have different permissions and functions. The system is divided into three subsystems according to the realization function, including the administrator, teacher, and student subsystem.

The administrator subsystem function is mainly responsible for the management of teachers and department information, including login system module, teacher management module, and department management module. In addition, Figure 6 indicates the structure diagram of the administrator module.

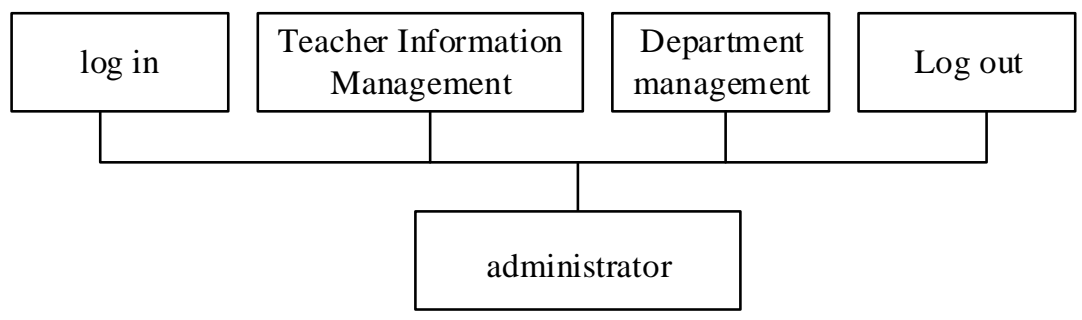

Fig. 6. Architecture diagram of the administrator module

The teacher subsystem mainly includes login system module, student management module, course management module, teaching resource module, homework management module, online Q\&A, online test, and score management. The structure diagram of the teacher module is shown in Figure 7. 


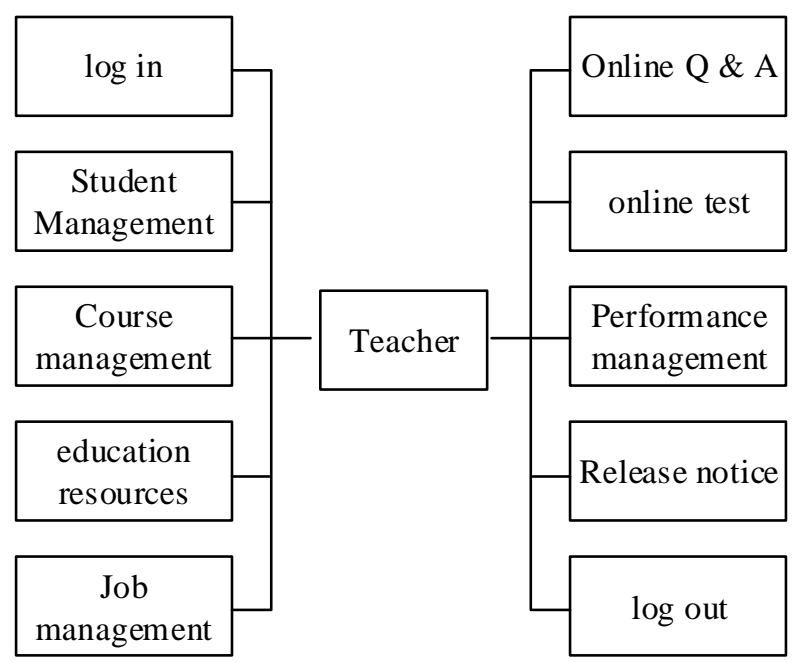

Fig. 7. The structure of the teacher module

The student subsystem mainly includes login system module, resource learning module, homework module, online Q\&A, online test, check notification, and logout. What's more, Figure 8 shows the structure diagram of the student module.

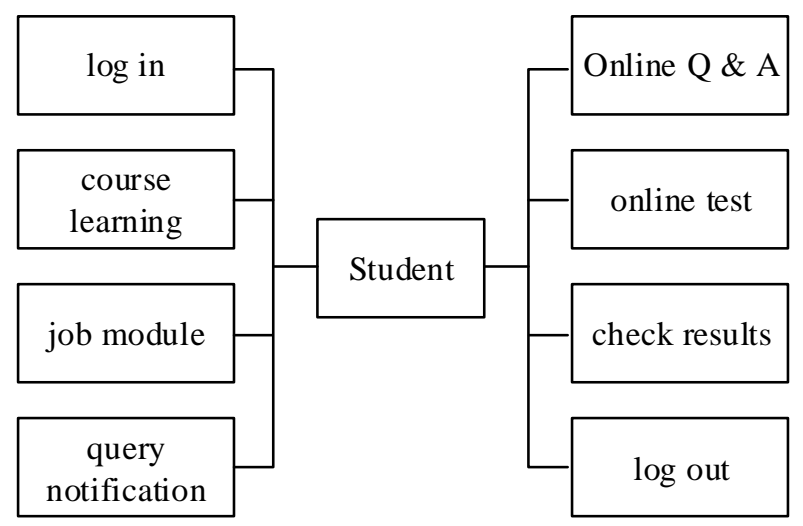

Fig. 8. Student module architecture diagram

Database design: Whether the database design is reasonable determines the execution efficiency of the system. During the design process, repeated data access should be avoided as much as possible, while data consistency and integrity should be ensured. The object of the system database operation in this study is the administrator and the teacher. The entities are set up with student entity, teacher entity, administrator entity, grade entity, course entity, test question database entity, question database entity, resource database entity, etc. There are three types of relationships between entities, which includes one-to-one, one-to-many, and many-to-many. 
Volume composition design: Online test module has two methods of test-paper generation, including manual test-paper generation and automatic test-paper generation. Manual test paper generation is suitable for staged chapter tests. The content of test papers is more targeted and the types of test questions are diverse, including filling in the blanks, selecting, and judging. Automatic test paper generation is to randomly select and combine test papers from the question bank according to the test paper setting requirements. The random selection algorithm and backtracking heuristics algorithm are used for the intelligent test paper composition, and backtracking heuristics algorithm is applied in this study. First, the teacher sets the type of test paper (score, number, type of question, and difficulty level), and the system extracts the test questions, saves the data in the LSB, and compares it with the database. If there are duplicate questions, the questions are selected again and whether the score meets the set requirements is automatically judged, until the completion of the test paper composition. The paper is previewed, saved, and stored as a word format test paper for later use.

\subsection{System test}

System testing is the process of evaluating the correctness and completeness of the system and analyzing whether it meets the design requirements. After the system is developed, it needs to be tested for each module. The black box testing is adopted to test the developed CAI based on AI. Mercury Loadrunner software is used for the stress test and the system analysis.

\section{Results}

\subsection{System function test results}

The functional test of ICAI is mainly to establish test cases based on the system development functions, and to check the functions step by step to see whether the system meets the user' functional requirements. Now the login module, homework release, and learning resource upload are taken as examples to display the results of the functional test.

The teacher module, student module, and administrator module of the system in this study all have the login function. After testing, the average response time is within $10 \mathrm{~s}$, and the response time of most transactions is less than $6 \mathrm{~s}$, and the system performance meets the design requirements. The test results are shown in Table 1. 
Table 1. Test results of login module

\begin{tabular}{|l|l|l|}
\hline \multicolumn{1}{|c|}{ Project } & \multicolumn{1}{c|}{ Expected results } & \multicolumn{1}{c|}{ Actual results } \\
\hline Entering user name & The system queries the user name by itself & Normal \\
\hline Entering password & The system queries the password by itself & Normal \\
\hline Choosing user type & The system checks the user type & Normal \\
\hline \multirow{2}{*}{ Log in } & Successful login & Normal \\
\cline { 2 - 3 } & Failed login, re-entering & Can't log in \\
\hline
\end{tabular}

The teacher's homework release sets 2 test states according to whether the teacher chooses the question bank. Besides, there are 3 states in the learning resource upload, including choosing to upload the file and fill in the information, filling in the information but not uploading the file, and choosing the file but not filling in the information. The performance of the tested system meets the design requirements, and Table 2 indicates the test results.

Table 2. Homework release and learning resource upload function test

\begin{tabular}{|l|l|l|}
\hline \multicolumn{1}{|c|}{ Project } & \multicolumn{1}{|c|}{ Expected results } & \multicolumn{1}{c|}{ Actual results } \\
\hline \multirow{2}{*}{ Homework release } & Successful & Students receive homework normally \\
\cline { 2 - 3 } & Failed to publish with no content & Please select content \\
\hline \multirow{2}{*}{$\begin{array}{l}\text { Learning resources } \\
\text { upload }\end{array}$} & Upload successfully & Normal \\
\cline { 2 - 3 } & Upload failed, prompt to fill in information & Prompt to fill in \\
\cline { 2 - 3 } & Upload failed, prompt to choose upload content & Can't upload \\
\hline
\end{tabular}

\subsection{System load performance test}

The load test of ICAI is mainly to determine whether the system can operate and work normally under a specific pressure. The recording content includes the scripts of the student module, teacher module, and management module. The test system is applied to open the script, and then start scheduling the virtual users, choose to create the script, and schedule the virtual users inside the interface. Mercury Loadrunner software is used in this study for stress tests to ICAI, and the simulated user volume is 200. Besides, Table 3 shows the test record results.

Table 3. Statistical results of stress test

\begin{tabular}{|c|l|l|l|l|}
\hline Numbering & \multicolumn{1}{|c|}{ System performance } & \multicolumn{1}{|c|}{ Specific description } & System response & Test results \\
\hline 1 & $\begin{array}{l}\text { Query of teaching infor- } \\
\text { mation }\end{array}$ & $\begin{array}{l}\text { Entering the required infor- } \\
\text { mation in the database to query }\end{array}$ & $\begin{array}{l}\text { Complete within } \\
5 \mathrm{~s}\end{array}$ & $\begin{array}{l}\text { Meeting } \\
\text { deadline }\end{array}$ \\
\hline 2 & Curriculum & $\begin{array}{l}\text { Add, delete, and modify course } \\
\text { information in the database }\end{array}$ & $\begin{array}{l}\text { Complete within } \\
3 \mathrm{~s}\end{array}$ & $\begin{array}{l}\text { Meeting } \\
\text { deadline }\end{array}$ \\
\hline 4 & Entry information check & $\begin{array}{l}\text { Check whether the input infor- } \\
\text { mation is correct }\end{array}$ & $\begin{array}{l}\text { Complete within } \\
1 \mathrm{~s}\end{array}$ & $\begin{array}{l}\text { Meeting } \\
\text { deadline }\end{array}$ \\
\hline 3 & $\begin{array}{l}\text { Upload statistics of student } \\
\text { assignments }\end{array}$ & $\begin{array}{l}\text { The system summarizes data- } \\
\text { base information }\end{array}$ & $\begin{array}{l}\text { Complete within } \\
10 \text { s }\end{array}$ & $\begin{array}{l}\text { Meeting } \\
\text { deadline }\end{array}$ \\
\hline 5 & $\begin{array}{l}\text { Teachers upload learning } \\
\text { resources }\end{array}$ & $\begin{array}{l}\text { Select resources and fill in the } \\
\text { information }\end{array}$ & $\begin{array}{l}\text { Complete within } \\
5 \mathrm{~s}\end{array}$ & $\begin{array}{l}\text { Meeting } \\
\text { deadline }\end{array}$ \\
\hline
\end{tabular}


Mercury Loadrunner software is adopted to measure the influence of different numbers of virtual users on the auxiliary teaching system. The number of virtual users is $1,50,100,200$ and 1,000, respectively. Figure 9 reveals that the system response delay is shorter when the number of users is small. When the concurrent user number increases, the response time of the system prolongs and there are increases in the number of users who can't successfully $\log$ in, the server CPU utilization, and the server memory utilization. After the above tests, the performance of the system meets the requirements of the software design, but it is necessary to have a comprehensive understanding of the system status in a specific environment.
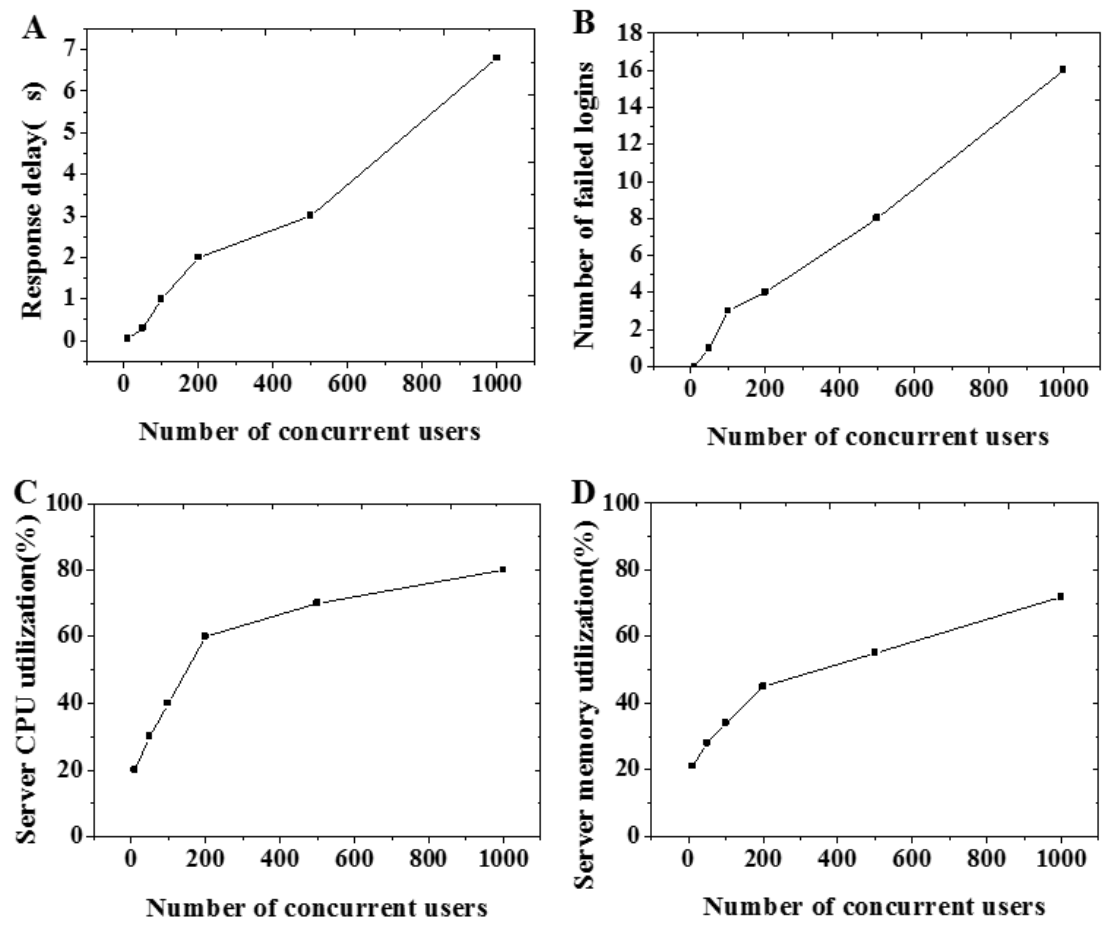

Fig. 9. System test results under different concurrent user numbers (A is response delay; B is number of users who can't log in; $\mathrm{C}$ is server CPU utilization; D is server memory utilization)

\section{Conclusion}

In the study, an intelligent auxiliary teaching system that combines AI and CAI is developed and designed, which adopts the B/S structure of browser, Web server and database server. In addition, JSP, Struts2, and SQL Server 2008 are also applied in this study, and the front desk function for students and the backstage management 
function for administrators and teachers are designed and realized. The test results show that the system designed in this study meets the requirements of software design, and the design and implementation of the system have reliable promotion value. However, this research still has some shortcomings. The system in this study is still in the trial test stage, and it needs to be run in a real environment to understand the overall status of the system, and continue to expand and improve the system knowledge base to improve the system knowledge base, to make it a real teaching system. Furthermore, the interaction between the various modules of the system needs to be strengthened, and the safety performance also needs to be improved. In summary, the research results of this study can provide ideas and references for the application of AI in CAI.

\section{$5 \quad$ References}

[1] Ameyaw, Y., Agbotse, S. (2016). Computer-Assisted Instruction (CAI) as an alternative instructional tool for improving the teaching and learning of blood circulation in humans. International Journal of Advanced Biological Research,6(2): 210-218.

[2] Limbong, T., Manullang, P., Napitupulu, E. (2017). Dikte Test Applications (IMLA) Using Computer Assisted Instruction (CAI) Model. Int. J. Eng. Res. Technol, 6(10): 384-388.

[3] Rosali, L J D. (2020). Effect of Computer-Assisted Instruction (CAI) on the Academic Achievement in Secondary Physics. Open Access Library Journal,7(05): 1.

[4] Sophia, C. J. (2019). Efficacy of concept mapping (CM) through computer assisted instruction (CAI) in nursing education. TNNMC Journal of Nursing Education and Administration, 7(2): 16-21.

[5] Guo, H. (2018). Application of a computer-assisted instruction system based on constructivism. International Journal of Emerging Technologies in Learning (iJET),13(04): 33-44.

[6] Ok, M. W., Bryant D. P., Bryant B. R. (2020). Effects of computer-assisted instruction on the mathematics performance of students with learning disabilities: A synthesis of the research. Exceptionality,28(1): 30-44. https://doi.org/10.1080/09362835.2019.1579723

[7] Wang, Q, Lu, P. (2019). Research on application of artificial intelligence in computer network technology. International Journal of Pattern Recognition and Artificial Intelligence,33(05): 1959015. https://doi.org/10.1142/s0218001419590158

[8] Zhao, Y., Xie, J. (2017). Artificial Intelligence, Computer Assisted Instruction in Basketball Training. International Journal of Information,9(1): 7.

[9] Suleiman, L., Buba, U., Sabo, M. S., et al. (2020). Effect of CAI Package on Achievement of Business Education Students in Small Business Management. ATBU Journal of Science, Technology and Education,8(2): 25-31.

[10] Yang F. J. (2019). The Session Inventory Module within an Intelligent Tutoring System for Data Normalization. International Journal of Advanced Computer Technology,8(6): 1318 .

[11] Benmoussa, K., Laaziri, M., Khoulji, S., et al. (2018). Intelligent system for the use of the scientific research information system. Int. J. Adv. Comput. Sci. Appl,9(6): 132-138.

[12] Hou, M., Fidopiastis, C. (2017). A generic framework of intelligent adaptive learning systems: from learning effectiveness to training transfer. Theoretical Issues in Ergonomics Science,18(2): 167-183. https://doi.org/10.1080/1463922x.2016.1166405 
[13] Wray, M., Houghton, A. M. (2019). Implementing disability policy in teaching and learning contexts-shop floor constructivism or street level bureaucracy? Teaching in Higher Education,24(4): 510-526. https://doi.org/10.1080/13562517.2018.1491838

[14] Ishihara, N., Funabiki, N., Kuribayashi, M., et al. (2017). A software architecture for Java programming learning assistant system. International Journal of Computer \& Software Engineering,2(1): 116. https://doi.org/10.15344/2456-4451/2017/116

[15] Sun, G., Wang, Y., Li, M., et al. (2018). A Lightweight MVC Framework Based on Code Decoupling Principle. Journal of Computer and Communications,6(3): 118-127. https://do i.org/10.4236/jcc.2018.63009

[16] Padovam, A. R. C., Pires, F. B. (2019). Experiência em migração do banco de dados MSSQL Server 2000 para 2014. Sínteses: Revista Eletrônica do SimTec,(7): e019079e019079. https://doi.org/10.20396/sinteses.v0i7.10304

[17] Setiyadi, D., Henderi, H., Arifin, R. W. (2020). Fungsi Date dalam Data Manipulation Language Dengan Bahasa Query Menggunakan SQL Server 2008. Informatics for Educators and Professional: Journal of Informatics,4(2): 163-172.

[18] Assis, J., Tyberghein, L., Bosch, S., et al. (2018). Bio-ORACLE v2. 0: Extending marine data layers for bioclimatic modelling. Global Ecology and Biogeography,27(3): 277-284. https://doi.org/10.1111/geb.12693

\section{Author}

Jingjing Zhang was born in QingDao, China, in 1985. From 2005 to 2009, She studied in Jingdezhen Ceramic University and received her bachelor's degree in 2009. From 2009 to 2012 she studied in China Academy of Art and received her Master's degree in 2012. Since 2012, she has worked in the School of Design and Art of Jingdezhen Ceramic University. She has published more than 10 academic papers publicly. Her research interests are included computer-aided education and computer-aided design. Email: zhnagjingjing-1227@163.com

Article submitted 2020-12-05. Resubmitted 2021-01-07. Final acceptance 2021-01-10. Final version published as submitted by the authors. 